\title{
Proficiency Tests for the NIST Airborne Asbestos. Program - 1991
}

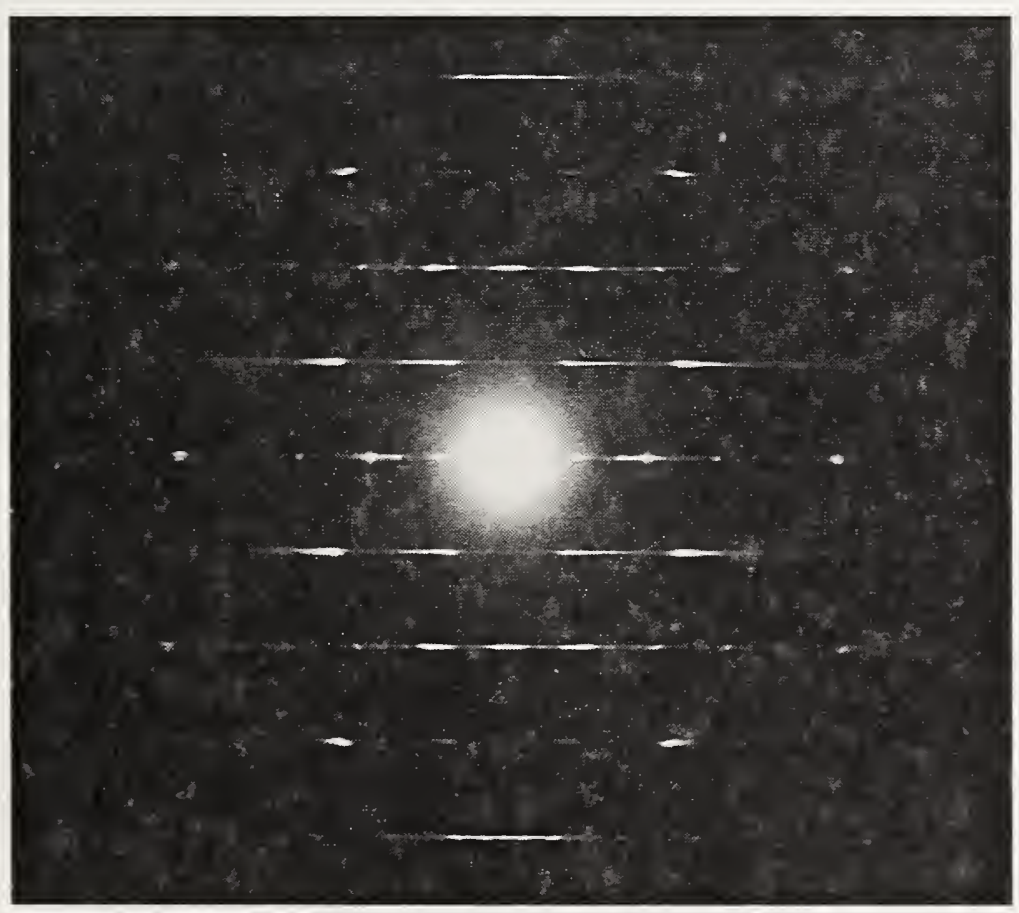

chrysotile diffraction pattern
Shirley Tumer

Eric B. Steel

Stacy S. Doom*

Steve B. Burris*

U.S. DEPARTMENT OF COMMERCE

Technology Administration

National Institute of Standards

and Technology

Microanalysis Research Group

Surface and Microanalysis Science Division Chemical Science \& Technology Laboratory

Gaithersburg, MD 20899

*Research Triangle Institute

Center for Environmental Measurements and Quality Assurance

Research Triangle Park, NC 27709-2194

May 1994
$-Q C$

100

.U56

NO. 5432

1994 



\section{NISTIR 5432}

\section{Proficiency Tests for the NIST Airborne Asbestos Program = 1991}

\author{
Shirley Tumer \\ Eric B. Steel \\ Stacy S. Doom* \\ Steve B. Burris*
}

U.S. DEPARTMENT OF COMMERCE

Technology Administration

National Institute of Standards and Technology

Microanalysis Research Group

Surface and Microanalysis Science Division Chemical Science \& Technology Laboratory

Gaithersburg, MD 20899

*Research Triangle Institute

Center for Environmental Measurements and Quality Assurance

Research Triangle Park, NC 27709-2194

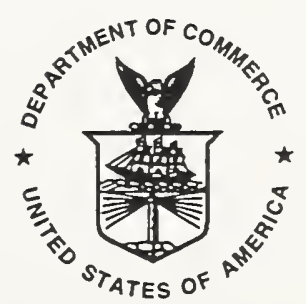

U.S. DEPARTMENT OF COMMERCE Ronald H. Brown, Secretary

TECHNOLOGY ADMINISTRATION

Mary L Good, Under Secretary for Technology

NATIONAL INSTITUTE OF STANDARDS

AND TECHNOLOGY

Aratl Prabhakar, Director 

The National Voluntary Accreditation Program (NVLAP) at the National Institute of Standards and Technology (NIST) has since 1990 had a program to accredit those laboratories involved in the analysis of airborne asbestos by transmission electron microscopy. As a part of that program, laboratories are sent proficiency tests twice yearly to evaluate their ability to correctly analyze samples and to test the general knowledge of laboratory personnel. The results of the tests are sent to the participating laboratories in the form of a summary report. This NIST Internal Report (NISTIR) contains the instructions and summary reports issued for the proficiency tests in 1991 (PT91-1, PT91-2). This NISTIR is one of a series covering the years of proficiency testing in the airborne asbestos accreditation program. The NISTIRs provide a historical record of materials sent to the laboratories for proficiency testing so that they can be referenced in other publications and so that background material can be given to those laboratories entering the accreditation program. The materials can also be used as educational aids. The material in the IRs are copies of the instructions and summary reports sent to the laboratories - if comments are warranted they are given on the chapter title page for the instructions or summary report. 



\section{Acknowledgements}

We thank Diane J. Hues of NIST for her assistance in PT91-2. 



\section{Table of Contents}

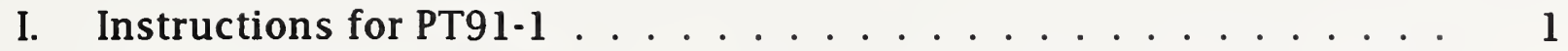

II. Summary Report for PT91-1 . . . . . . . . . . . . . . . . . . 23

III. Instructions for PT91-2 . . . . . . . . . . . . . 35

IV. Summary Report for PT91-2 . . . . . . . . . . . . . 41 

I. Instructions for PT91-1 
Proficiency test 91-1 Part 1 - EDS analysis

Instructions for evaluation of EDS spectra

Enclosed are EDS spectra labelled Figures 1-4 with associated tables labelled Tables 1-5. Descriptions of the spectra and tables are given below:

Figure 1a - spectrum plotted on a linear scale with peaks labelled $1-14$

Figure $1 \mathrm{~b}$ - spectrum of Figure 1a plotted on a log scale with peaks labelled $1-14$

Table 1 - listing of energy, peak counts and background counts for the peaks in Fig. 1a,b

Figure 2 - spectrum showing a $\mathrm{Mn} \mathrm{Ka}$ peak

Table 2 - listing of the total counts and energy for each channel in Fig. 2

Figure 3 - spectrum from Standard Reference Material (SRM) 2063

Table 3 - listing of the chemical composition of SRM 2063

Table 4 - listing of the energy, peak counts and background counts for the peaks in Fig. 3

Figure 4a - spectrum from SRM 2063 (linear scale)

Figure $4 \mathrm{~b}$ - spectrum of Figure 4a plotted on a log scale

Table 5 - listing of the energy, peak counts and background counts for the peaks in Fig. 4a,b

Carefully follow the instructions below for deriving and recording values from each spectrum.

\section{Figure 1}

For this spectrum, record on Form 3 the source of the $x$-ray peaks labelled from 1 - 14. Note: there are no peaks in the spectrum above $10 \mathrm{keV}$. Include the element and peak type (K, L.., $\alpha, \beta$, etc.) for example, $\mathrm{Zn} \mathrm{Ka}$ or $\mathrm{Y} \mathrm{L} \beta$. If there is more than one possibility that is supported by the spectrum, list them in order of most likely to least likely.

\section{Figure 2}

From this spectrum and the information given in Table 2, determine the resolution (FWHM) of the detector used to collect the spectrum. Record any work done on Form 1. Record the value for the resolution on Form 3 (to the nearest $\mathrm{eV}$ ).

\section{Figure 3}

From this spectrum of SRM 2063 and the information given in Tables 3 and 4, calculate the k-values for each element (relative to $\mathrm{Si}$ ). Record the method used and any work done on Form 2. Record the $\mathrm{k}$-values on Form 3 (to two decimal places).

\section{Figure 4}

This spectrum was also collected from SRM 2063. Answer the questions on Form 3 concerning this spectrum. 


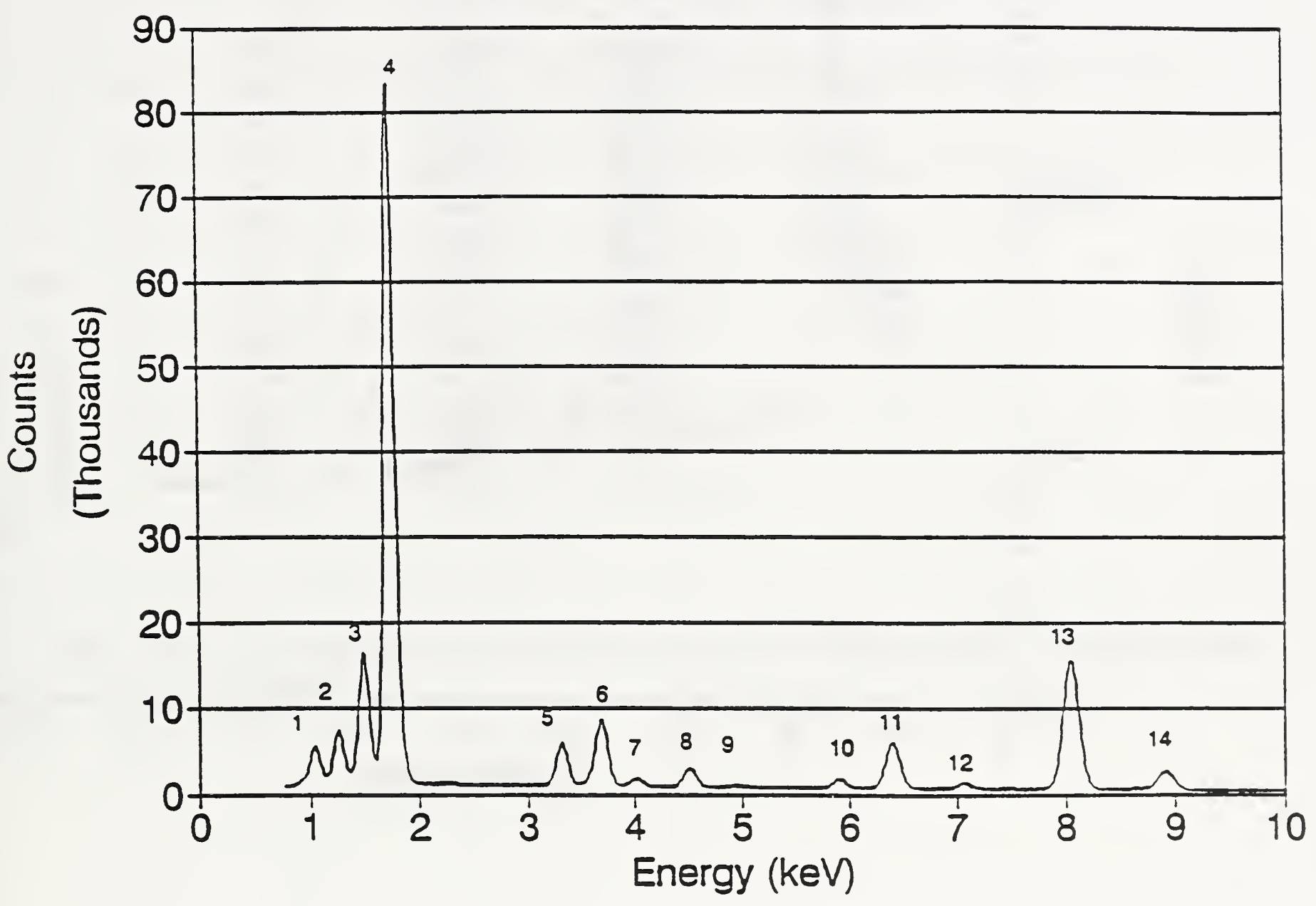

Figure 1a. Spectrum plotted on a linear scale with peaks labelled 1-14. 


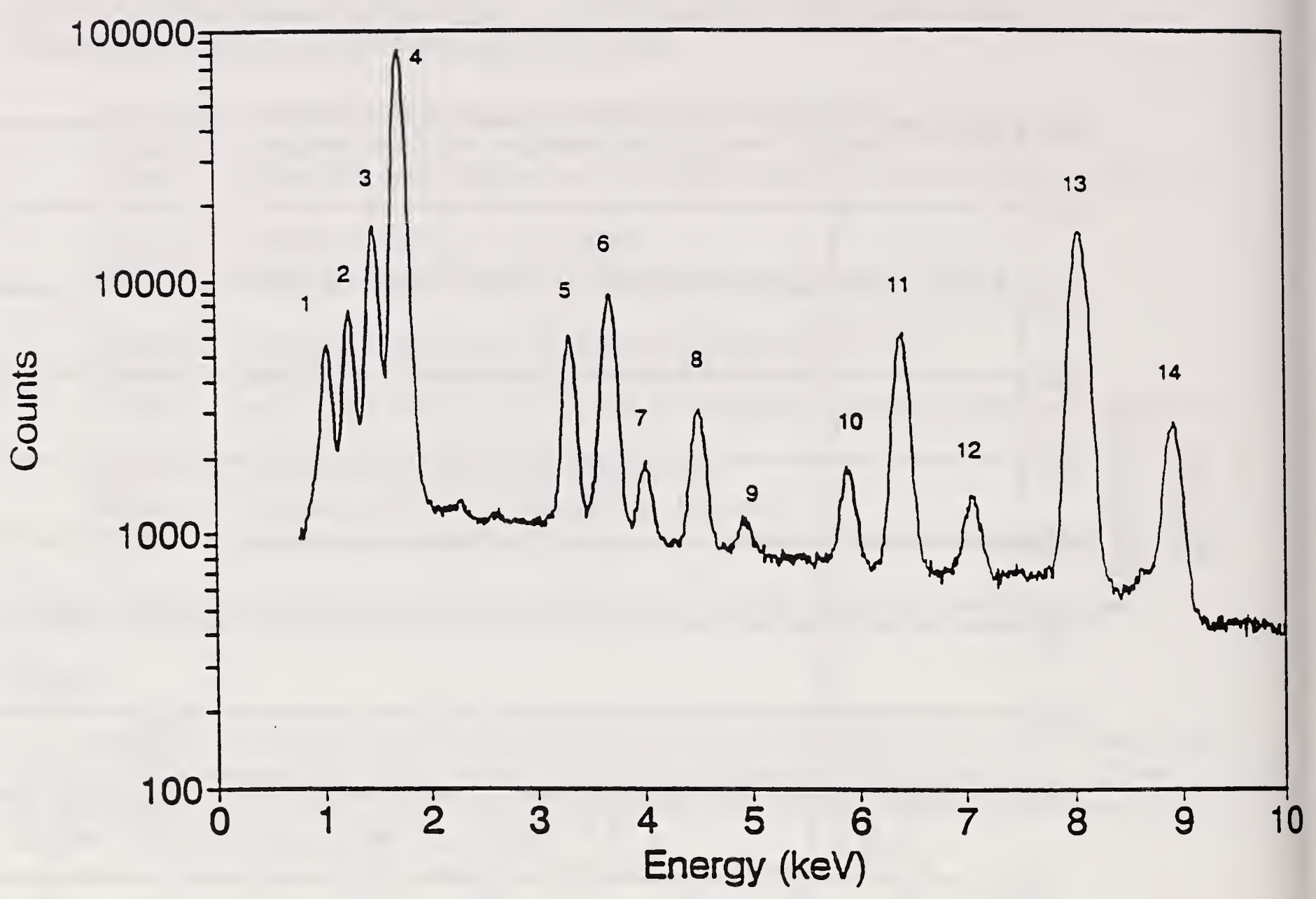

Figure 1b. Spectrum plotted on a log scale with peaks labelled 1-14. 
Table 1. Listing of the energy, peak counts (background subtracted) and the background counts for the peaks in Figure 1

$\begin{array}{llll}\text { Peak } & \text { Energy } & \begin{array}{l}\text { Peak } \\ \text { Counts* }\end{array} & \begin{array}{l}\text { Background } \\ \text { Counts }\end{array} \\ 1 & 1.04 & 31524 & 46916 \\ 2 & 1.25 & 48190 & 53082 \\ 3 & 1.49 & 150093 & 68297 \\ 4 & 1.74 & 946893 & 64349 \\ 5 & 3.31 & 64010 & 40436 \\ 6 & 3.69 & 107404 & 44180 \\ 7 & 4.01 & 11060 & 30167 \\ 8 & 4.51 & 31161 & 37135 \\ 9 & 4.93 & 4499 & 26635 \\ 10 & 5.89 & 15780 & 33682 \\ 11 & 6.40 & 87816 & 40171 \\ 12 & 7.06 & 12304 & 32947 \\ 13 & 8.04 & 263856 & 43055 \\ 14 & 8.91 & 38523 & 36763\end{array}$

*Note: Peak counts are the number of counts in the peak integral with the background counts subtracted out 


\section{Manganese K-alpha Peak for X-ray Spectrometer Calibration}

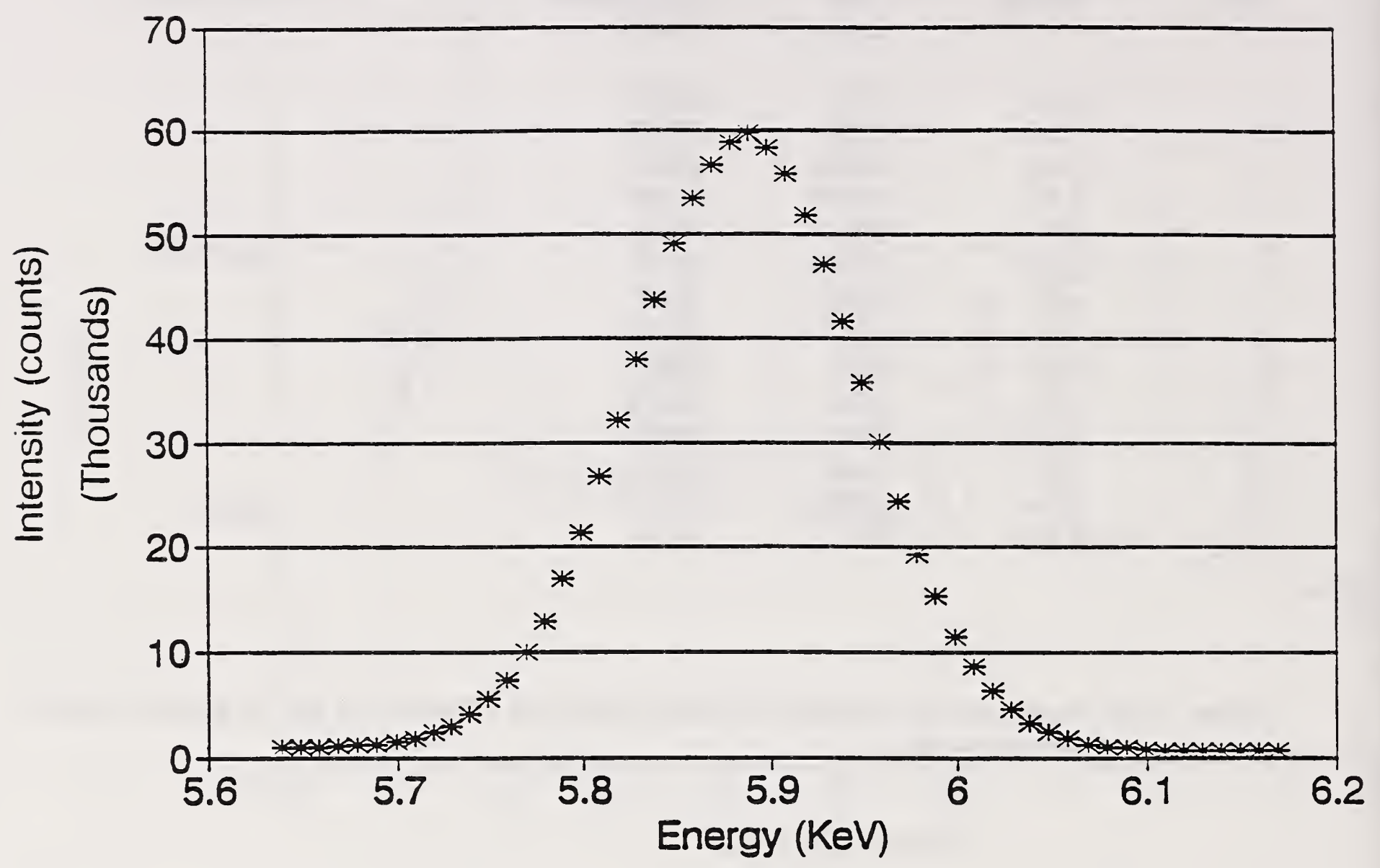

Figure 2. Spectrum showing a Mn K-alpha peak. 
Table 2. Listing of the total counts and energy for each channel in Figure 2.

\begin{tabular}{|c|c|c|}
\hline CHANNEL & COUNTS & ENERGY (keV) \\
\hline 547 & 905 & 5.639 \\
\hline 548 & 911 & 5.649 \\
\hline 549 & 1011 & 5.659 \\
\hline 550 & 1040 & 5.669 \\
\hline 551 & 1174 & 5.679 \\
\hline 552 & 1299 & 5.689 \\
\hline 553 & 1564 & 5.699 \\
\hline 554 & 1824 & 5.709 \\
\hline 555 & 2352 & 5.719 \\
\hline 556 & 2959 & 5.729 \\
\hline 557 & 4106 & 5.739 \\
\hline 558 & 5635 & 5.749 \\
\hline 559 & 7367 & 5.759 \\
\hline 560 & 10040 & 5.769 \\
\hline 561 & 12911 & 5.779 \\
\hline 562 & 17030 & 5.789 \\
\hline 563 & 21366 & 5.799 \\
\hline 564 & 26742 & 5.809 \\
\hline 565 & 32099 & 5.819 \\
\hline 566 & 38060 & 5.829 \\
\hline 567 & 43673 & 5.839 \\
\hline 568 & 49027 & 5.849 \\
\hline 569 & 53403 & 5.859 \\
\hline 570 & 56663 & 5.869 \\
\hline 571 & 58883 & 5.879 \\
\hline 572 & 59780 & 5.889 \\
\hline 573 & 58292 & 5.899 \\
\hline 574 & 55822 & 5.909 \\
\hline 575 & 51858 & 5.919 \\
\hline 576 & 46989 & 5.929 \\
\hline 577 & 41598 & 5.939 \\
\hline 578 & 35760 & 5.949 \\
\hline 579 & 30101 & 5.959 \\
\hline 580 & 24424 & 5.969 \\
\hline 581 & 19290 & 5.979 \\
\hline 582 & 15422 & 5.989 \\
\hline 583 & 11501 & 5.999 \\
\hline 584 & 8615 & 6.009 \\
\hline 585 & 6288 & 6.019 \\
\hline 586 & 4638 & 6.029 \\
\hline 587 & 3314 & 6.039 \\
\hline 588 & 2455 & 6.049 \\
\hline 589 & 1815 & 6.059 \\
\hline 590 & 1310 & 6.069 \\
\hline 591 & 1003 & 6.079 \\
\hline 592 & 895 & 6.089 \\
\hline 593 & 741 & 6.099 \\
\hline 594 & 691 & 6.109 \\
\hline 595 & 676 & 6.119 \\
\hline 596 & 623 & 6.129 \\
\hline 597 & 634 & 6.139 \\
\hline 598 & 624 & 6.149 \\
\hline 599 & 613 & 6.159 \\
\hline 600 & 634 & 6.169 \\
\hline
\end{tabular}




\section{K-value Test X-ray Spectrum}

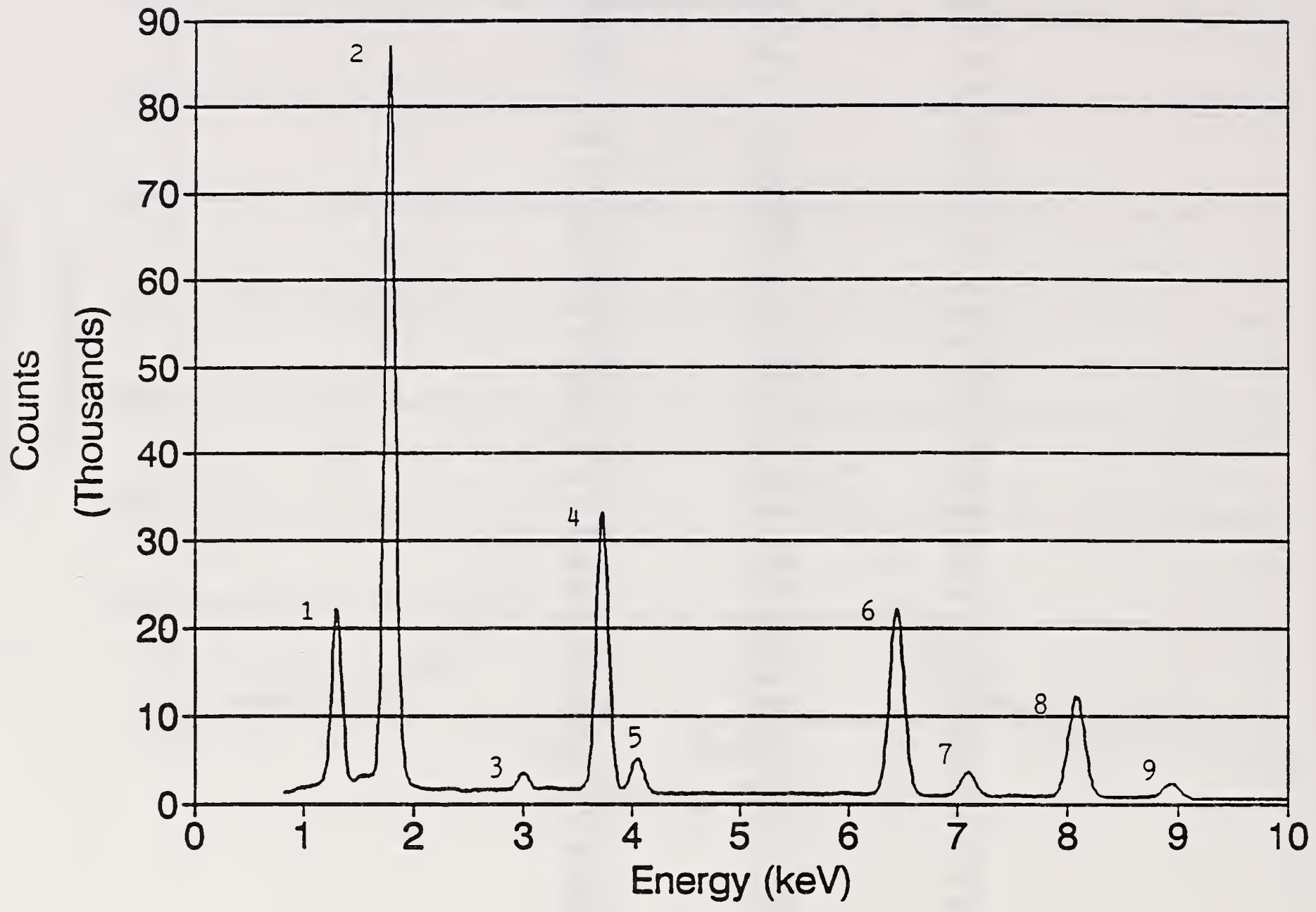

Figure 3. Spectrum from Standard Reference Material (SRM) 2063 
NIST AIR PROGRAM PROFICIENCY TEST $4 / 91$

Table 3. Listing of the chemical composition of SRM 2063

$\begin{array}{lccc}\text { Element } & \begin{array}{l}\text { Weight \% } \\ \text { oxide }\end{array} & \begin{array}{l}\text { Weight \% } \\ \text { element }\end{array} & \begin{array}{l}\text { Atom \% } \\ \text { element }\end{array} \\ \mathrm{O} & -. & 42.4 & 60.3 \\ \mathrm{Mg} & 14.7 & 8.8 & 8.2 \\ \mathrm{Si} & 54.3 & 25.4 & 20.3 \\ \mathrm{Ar} & 1.0 & 1.0 & 0.7 \\ \mathrm{Ca} & 15.5 & 11.1 & 6.2 \\ \mathrm{Fe} & 14.4 & 11.2 & 4.4 \\ & & & \\ \text { Total } & 99.9 & 99.9 & 100.1\end{array}$


Table 4. Listing of the energy, peak counts (background subtracted) and the background counts for the peaks in Figure 3

$\begin{array}{llcl}\text { Peak } & \text { Energy } & \begin{array}{l}\text { Peak } \\ \text { Counts* }\end{array} & \begin{array}{l}\text { Background } \\ \text { Counts }\end{array} \\ 1 & 1.25 & 213242 & 87854 \\ 2 & 1.74 & 980256 & 76855 \\ 3 & 2.96 & 24078 & 57696 \\ 4 & 3.69 & 434036 & 55295 \\ 5 & 4.01 & 57779 & 44936 \\ 6 & 6.40 & 341445 & 56117 \\ 7 & 7.06 & 47234 & 39791 \\ 8 & 8.04 & 200347 & 52307 \\ 9 & 8.91 & 31255 & 45400\end{array}$

*Note: Peak counts are the number of counts in the peak integral after the background counts have been removed 
NIST AIR PROGRAM PROFICIENCY TEST 4/91

\section{Linear Scale}

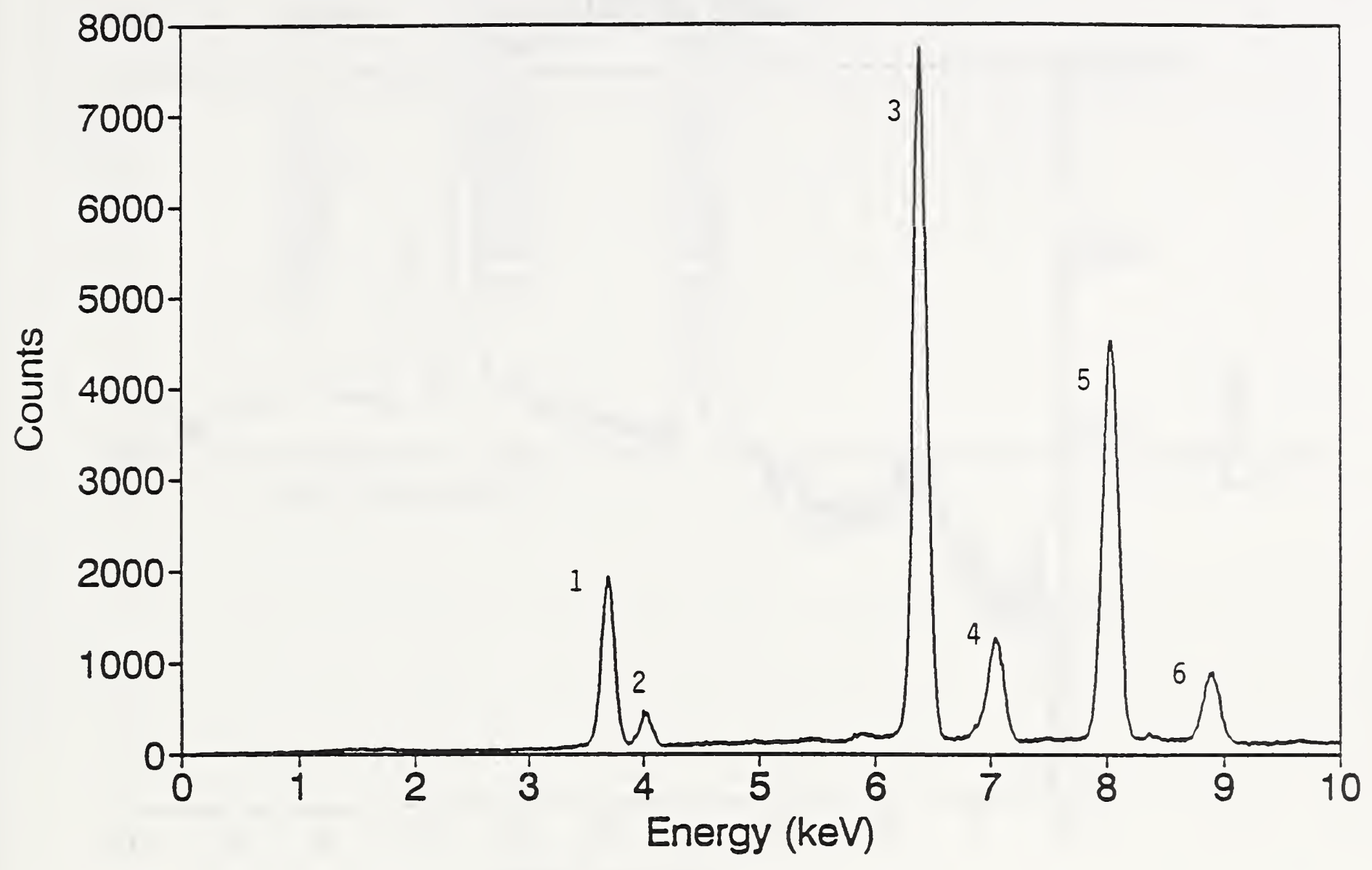

Figure 4a. Spectrum from SRM 2063 (linear scale). 


\section{Log Scale}

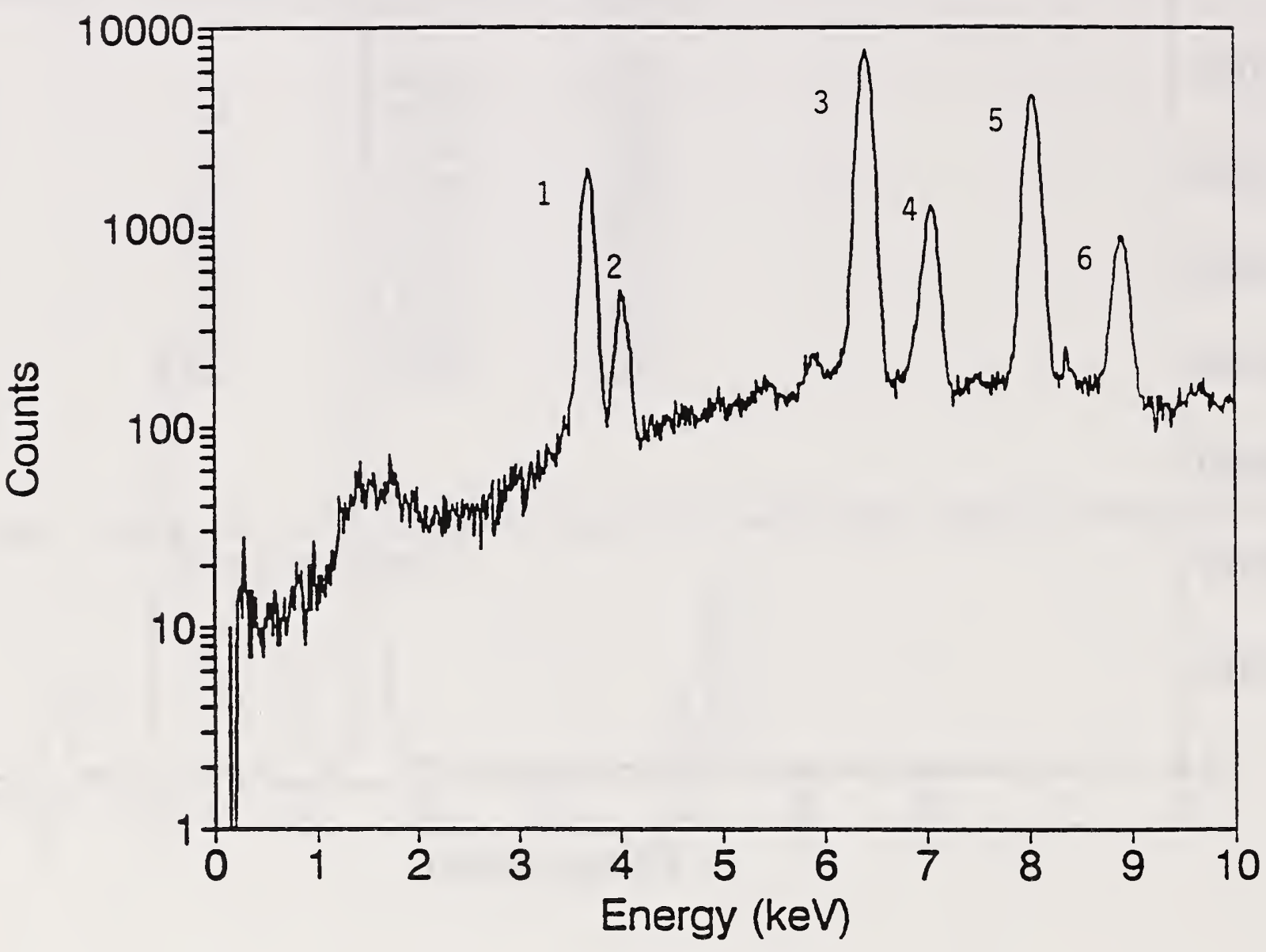

Figure 4b. Spectrum from SRM 2063 (log scale). 
NIST AIR PROGRAM PROFICIENCY TEST $4 / 91$

Table 5. Listing of the energy, peak counts (background subtracted) and the background counts for the peaks in Figure 4.

$\begin{array}{llll}\text { Peak } & \text { Energy } & \begin{array}{l}\text { Peak } \\ \text { Counts }\end{array} & \begin{array}{l}\text { Background } \\ \text { Counts }\end{array} \\ 1 & 3.69 & 18770 & 2399 \\ 2 & 4.01 & 3873 & 2493 \\ 3 & 6.40 & 85190 & 8306 \\ 4 & 7.06 & 14265 & 6559 \\ 5 & 8.04 & 53341 & 7332 \\ 6 & 8.91 & 9806 & 6542\end{array}$

*Note: Peak counts are the number of counts in the peak integral after the background counts have been removed 


\section{Form 1}

1. Briefly outline the method used to determine the resolution for the peak in Figure 2.

2. Show work involved in calculation of resolution (attach another page if necessary). 


\section{Form 2}

1. Describe briefly the method used for calculating the k-values for the peaks in Figure 3.

2. Show work done in calculation of $k$-values (attach another page if necessary). 
Form 3

Figure 1

\begin{tabular}{|c|c|c|c|}
\hline Peak number & $\begin{array}{l}\text { Peak identification } \\
\text { Choice \#1 }\end{array}$ & $\begin{array}{c}\text { Peak identification } \\
\text { Choice } \# 2\end{array}$ & $\begin{array}{l}\text { Peak identification } \\
\text { Choice \#3 }\end{array}$ \\
\hline 1 & & & \\
\hline 2 & & & \\
\hline 3 & & & \\
\hline 9 & & & \\
\hline 5 & & & \\
\hline 9 & & & \\
\hline 7 & & & \\
\hline 9 & & & \\
\hline 9 & & & \\
\hline 10 & & & \\
\hline 10 & & & \\
\hline 12 & & & \\
\hline 13 & & & \\
\hline 14 & & & \\
\hline
\end{tabular}


Form 3 (continued)

Figure 2

Resolution of the detector $(\mathrm{eV})$

Figure 3

\begin{tabular}{|c|c|}
\hline Element & k-value \\
\hline $\mathrm{Mg}$ & \\
\hline $\mathrm{Si}$ & \\
\hline $\mathrm{Ca}$ & \\
\hline $\mathrm{Fe}$ & \\
\hline
\end{tabular}


Form 3 (continued)

Figure 4 (collected from SRM 2063)

1. What features are abnormal about this spectrum? (compare to Figure 3 and use information from Table 3)

2. How would one know that the spectrum was abnormal if the chemistry of the material was not known?

Give at least one possible explanation for the cause of the abnormal spectrum of Figure 4 for the following cases.

3. The abnormal spectrum is collected from all areas observed on an SRM 2063 sample.

4. The abnormal spectrum is collected from one area of an SRM 2063 sample - other areas observed before and after the abnormal spectrum give the "normal" spectrum as shown in Figure 3. 
Form 4

1) Figure 5 is a color copy of a print of a diffraction grating replica which contains 2160 lines $/ \mathrm{mm}$. Determine the total magnification of the replica. In the space below, list any measured distances in $\mathrm{mm}$ and show the work done to calculate the magnification and the standard deviation of this value (if multiple measurements were made). Enter the total magnificaton and standard deviation in the spaces provided.

Total magnification

Standard deviation 
NIST AIR PROGRAM PROFICIENCY TEST $4 / 91$

Lab Code

Form 4 (cont'd)

2) In the space below, please describe the method used to calibrate the magnification of the transmission electron microscope(s) in your laboratory. 
Figure 5

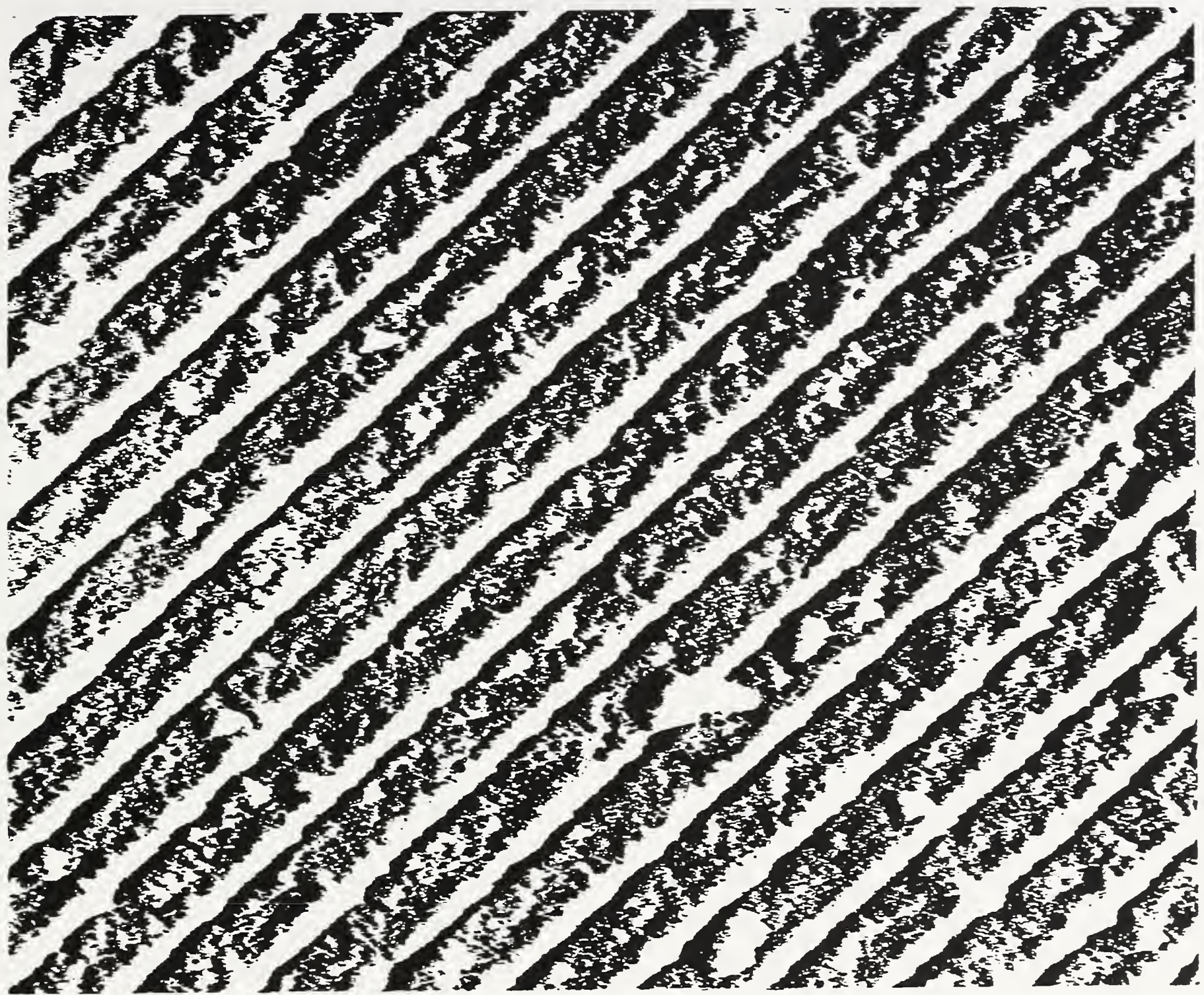

Diffraction grating replica 
Page 22 of 46 
II. Summary Report for PT91-1

This summary report states that 32 laboratories did not pass this proficiency test. There was a change in the grading after laboratories reported that an incorrect formula for $k$-values was given at a course for asbestos analysis. After eliminating the points deducted for incorrect $\mathrm{k}$-values, only three laboratories did not pass this test. 
The information presented in this report is a summary of the results and performance of laboratories on the proficiency test distributed in April of 1991 (designated as test 91-1). Discussion of the responses to the problems in this proficiency test is given in the main portion of the report. Suggestions for further reading are given in Appendix A. The results obtained by the laboratory receiving this report are given in Appendix B.

\section{Part 1. Identification of peaks on a spectrum}

From the spectrum given in Figure 1 and from the information given in Table 1 of the proficiency test, laboratories were asked to identify the peaks labelled 1-14. An identification of a peak included reporting the element and the peak type $(\mathrm{K} \alpha, \mathrm{K} \beta, \mathrm{L} \alpha$, etc.). The correct responses are given in the following table.

\begin{tabular}{|c|c|c|c|}
\hline Peak number & $\begin{array}{l}\text { Peak identification } \\
\text { Choice \#1 }\end{array}$ & $\begin{array}{c}\text { Peak identification } \\
\text { Choice \#2 }\end{array}$ & $\begin{array}{c}\text { Peak identification } \\
\text { Choice \#3 }\end{array}$ \\
\hline 1 & $\mathrm{Na} \mathrm{Ka}(\mathrm{K} \beta)$ & $(\mathrm{Cu} L \alpha, L \beta)$ & none \\
\hline 8 & $\mathrm{Mg} \mathrm{Ka}(\mathrm{K} \beta)$ & none & none \\
\hline 3 & $\mathrm{Al} \mathrm{Ka}(\mathrm{K} \beta)$ & none & none \\
\hline 8 & Si Ka $(K \beta)$ & none & none \\
\hline 5 & $\mathrm{~K} \mathrm{Ka}$ & none & none \\
\hline 8 & $\mathrm{Ca} \mathrm{Ka}$ & $(\mathrm{K} \mathrm{K} \beta)$ & none \\
\hline 7 & $\mathrm{Ca} \mathrm{K} \beta$ & none & none \\
\hline 8 & $\mathrm{Ti} \mathrm{Ka}$ & none & none \\
\hline 9 & $\mathrm{Ti} \mathrm{K} \beta$ & none & none \\
\hline 10 & $\mathrm{Mn} \mathrm{Ka}$ & mone & none \\
\hline 11 & $\mathrm{Fe} \cdot \mathrm{Ka}$ & $(\mathrm{Mn} \mathrm{K} \beta)$ & none \\
\hline 10 & $\mathrm{Fe} \mathrm{K} \beta$ & mone & none \\
\hline 13 & $\mathrm{Cu} \mathrm{Ka}$ & none & none \\
\hline 14 & $\mathrm{Cu} \mathrm{K} \beta$ & none & none \\
\hline
\end{tabular}

In this table, minor peaks are indicated by parentheses. It was stated in the instructions that no peaks were present in the spectrum that were greater than $10 \mathrm{keV}$. Therefore, no L lines other than for $\mathrm{Cu}$ should have been indicated by the laboratories for this spectrum.

\section{- Evaluation}

The identification of each peak type is worth one point. Partial credit was given if the element was correctly identified but the electron-transition designation $(K, L$ or $\alpha, \beta)$ was incorrect $(-0.25$ for each incorrect designation). For $\mathrm{Na}, \mathrm{Mg}, \mathrm{Al}$ and $\mathrm{Si}$ no points were deducted if a laboratory reported $\mathrm{K}$ as the peak type instead of $\mathrm{Ka}$. Partial credit ( 0.5 points) was given to laboratories if they reported 
a possible $\mathrm{L}$ or $\mathrm{K}$ line as their first choice and the correct $\mathrm{K}$ line as their second choice. The second and third choices of the laboratories were not otherwise evaluated.

\section{Part 2. Determination of detector resolution}

The laboratories were given a copy of a spectrum showing a $\mathrm{Mn} \mathrm{Ka}$-ray peak (Figure 2 in the proficiency-test instructions) and a table listing the channels, the counts per channel and the corresponding energies (Table 2) for each point in the spectrum. The laboratories were asked to determine to the nearest $\mathrm{eV}$, the resolution at FWHM of the detector used to collect the spectrum. The correct answers include one of the following:

\begin{tabular}{|c|c|}
\hline Conditions & Resolution \\
\hline Without background subtraction & $144 \mathrm{eV}$ \\
\hline With background subtraction & $145 \mathrm{eV}$ \\
\hline
\end{tabular}

Many laboratories obtained values other than those above because approximate methods for determining detector resolution were used. A range of values from 140-160 eV was accepted for the resolution because the method for resolution determination and the expected accuracy are not specified in the NVLAP Program handbook for airborne asbestos analysis (Steel et al., 1989). A discussion of two acceptable methods for obtaining peak resolutions are given below.

- Method 1 - Interpolation of values in Table 2

To determine the resolution of the detector using interpolation of the data in Table 2 of the proficiency-test instructions (without subtraction of background), the following steps can be taken:

1) Determine the maximum number of counts for a channel in the spectrum.

2) Divide this value by 2 to obtain the value for the half maximum.

3) Find on Table 2 the range of counts and energies within which the half maximum falls for both the low and high energy sides of the peak. Label the energies of the channels bracketing the half maximum on the low energy side as $A$ and $B$ (where $B$ is the higher energy). Similarly, label the channels bracketing the half maximum on the high energy side as $C$ and $D$ (where $D$ has the higher energy). The counts for the corresponding energies are labelled as a, b, $c$ and $d$ (see Figure 1 on the following page).

4) Use interpolation to obtain the energies corresponding to the half maximum values on the low and high energy sides of the peak. For the interpolation, the following formula can be used determine the resolution:

$$
\text { Resolution }=\frac{b-h m}{b-a} \cdot 10 \mathrm{eV}+\frac{c-h m}{c-d} \cdot 10 \mathrm{eV}+(C-B) \mathrm{eV}
$$

where $a, b, c, d, B$ and $C$ were defined in the step above and hm equals the number of counts at half maximum. 


\section{Manganese K-alpha Peak for X-ray Spectrometer Calibration}

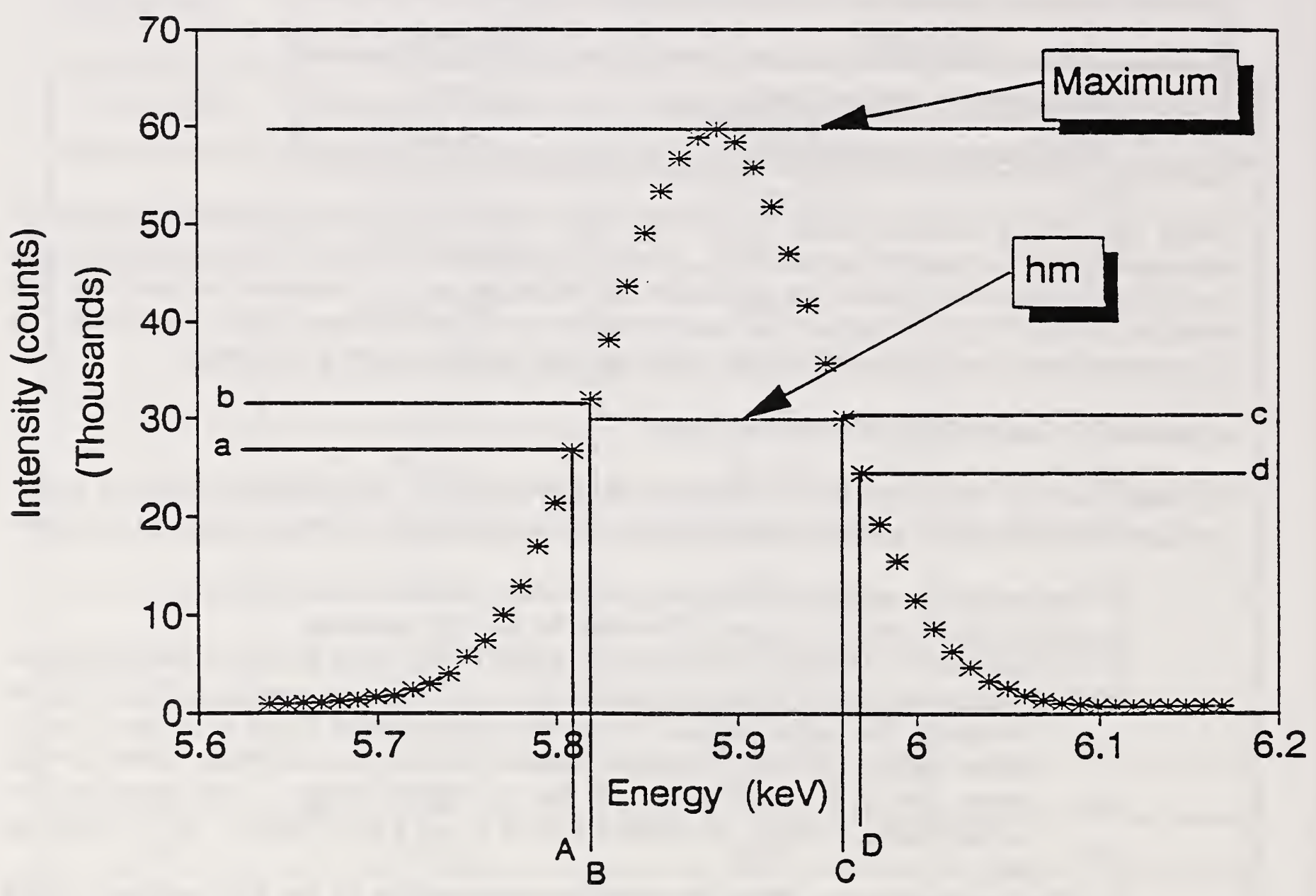

Figure 1. Illustration of the location of the energies (A, B, C and D) and counts ( $a, b, c$ and $d)$ discussed in Method 1 for the determination of detector resolution. 
Following this procedure for the peak given in Figure 2 and the values given in Table 2 of the proficiency test instructions leads to the following:

1) The maximum number of counts in a channel in Table 2 is 59780 (in channel 572).

2) Half of this value is 29890 .

3) On the low energy side of the peak the half maximum falls within the following values:

\begin{tabular}{|c|c|c|}
\hline Channel & Counts & Energy \\
\hline 564 & 26742 & 5.809 \\
\hline 565 & 32099 & 5.819 \\
\hline
\end{tabular}

On the high energy side of the peak, the half maximum falls within the following values:

\begin{tabular}{|c|c|c|}
\hline Channel & Counts & Energy \\
\hline 579 & 30101 & 5.959 \\
\hline 580 & 24424 & 5.969 \\
\hline
\end{tabular}

4) To determine the resolution, the values above are put into equation 1 as follows:

$$
\text { Resolution }=\frac{32099-29890}{32099-26742} \cdot 10 \mathrm{eV}+\frac{30101-29890}{30101-24424} \cdot 10 \mathrm{eV}+140 \mathrm{eV}=144.49 \mathrm{eV}^{(2)}
$$

Rounding this number to the nearest $\mathrm{eV}$, a value for the detector resolution of $144 \mathrm{eV}$ is obtained.

Note: This method can be easily used with background subtracted counts. The values for the maximum number of counts, the half maximum and a, b, c and $d$ will be slightly reduced by the background subtraction.

Method 2 - Estimation from physical measurement of the peak

Some laboratories derived the actual resolution by measuring distances on the peak The following steps are followed:

1) The height of the peak is measured on the spectrum in $\mathrm{mm}$ or $\mathrm{cm}$.

2) Half the height measured above is determined and a line is drawn through the peak at that height.

3) At the two places where the line intersects the peak, perpendicular lines are drawn that intersect the $x$ axis (containing the energy in $\mathrm{eV}$ ).

4) The physical distance (d) between the two lines is noted in $\mathrm{mm}$ or $\mathrm{cm}$. The physical distance (D) between two arbitrarily chosen energies on the $\mathrm{x}$ axis is measured. The difference between the energies is determined $(E)$.

5) The resolution is determined by solving for $\mathbf{x}$ in the following equation: 


$$
\frac{d}{x}=\frac{D}{E}
$$

This method can give acceptable results if applied carefully. However, method 1 is preferable.

\section{Comments}

The resolution of an $\mathrm{x}$-ray detector affects the degree of overlap between adjacent peaks in a spectrum and the detection limit of minor peaks. One of the requirements of the NVLAP handbook (Steel et al, 1989) is that the detector shall have a resolution of $175 \mathrm{eV}$ or better at $\mathrm{Mn} \mathrm{Ka}$. For this requirement a reasonably accurate determination of the resolution value (to within $\pm 2 \mathrm{eV}$ ) is assumed. Without such accuracy, significant under estimation may occur, e.g., a detector with approximately $185 \mathrm{eV}$ resolution may be improperly calculated to have a resolution of $170 \mathrm{eV}$. To obtain such accuracy, at least 5,000 counts for the peak height should be accumulated to obtain adequate counting statistics and an appropriate method for resolution determination should be used. Methods in which resolution is estimated to the nearest channel $(10 \mathrm{eV})$ should not be used. Similarly, methods in which a theoretical resolution is calculated based on electronic noise and the peak energy should not be used.

There is software available (some of which is associated with detector-multichannel analyzer systems) that will calculate the resolution of a peak. For some programs, a Gaussian curve is fitted to the peak so that the top of the peak and the FWHM can be accurately determined. This software should be used to monitor detector resolution only if periodically verified by Method 1 above.

A range of values for the resolution of $140-160 \mathrm{eV}$ was considered acceptable for this proficiency test. This range was chosen because resolutions of 140,150 or $160 \mathrm{eV}$ can be obtained by estimation to the nearest channel. As stated above, this method should not be used to determine the resolution of detectors used in the laboratory.

- Evaluation

The value determined for the resolution is worth one point.

\section{Part 3. Determination of $k$-values}

For this part of the proficiency test, laboratories were asked to determine $\mathrm{k}$-values for $\mathrm{Mg}, \mathrm{Si}, \mathrm{Ca}$, and $\mathrm{Fe}$ based on information given in Tables 3 and 4 and Figures $4 \mathrm{a}$ and $\mathrm{b}$ of the proficiency test. Correct values are given in the following table:

\begin{tabular}{|c|c|}
\hline Element & k-value \\
\hline $\mathrm{Mg}$ & 1.59 \\
\hline $\mathrm{Si}$ & 1.00 \\
\hline $\mathrm{Ca}$ & 0.99 \\
\hline $\mathrm{Fe}$ & 1.27 \\
\hline
\end{tabular}


- Method

To determine $\mathrm{k}$-values relative to $\mathrm{Si}$, the following formula is used:

$$
\frac{C_{A}}{C_{S i}}=k_{A S i} \cdot \frac{I_{A}}{I_{S i}}
$$

where A represents the element of interest, $C$ is the concentration of element $A$ in weight percent, and $I$ is the intensity of the characteristic peak corresponding to the element. Solving for $k_{A S i}$ :

$$
k_{A S i}=\frac{C_{A}}{C_{S i}} \cdot \frac{I_{S i}}{I_{A}}
$$

As an example, the $\mathrm{k}$-value for $\mathrm{Mg}$ is obtained as follows:

$$
k_{M g S i}=\frac{8.8}{25.4} \cdot \frac{980256}{213242}=1.59
$$

Common errors made by the laboratories include the use of atomic $\%$ element or weight $\%$ oxide for the concentration, use of no concentration information (just peak intensities), and determining the reciprocal of the value for the $\mathrm{k}$-values.

Note: It is recommended that the $\mathrm{k}$-values for $\mathrm{Na}, \mathrm{Mg}, \mathrm{Al}$, and $\mathrm{Si}$ be determined using the total peak integral (the $\mathrm{K} \alpha+\mathrm{K} \beta$ ) while the $\mathrm{k}$-values for $\mathrm{Ca}$ and $\mathrm{Fe}$ be determined using the intensities of only the $\mathrm{K} \alpha$ peak. This approach of using the integral of a single peak is recommended because the separate handling of the $\mathrm{K} \beta$ peak takes more processing steps and has the potential to introduce errors to the measurement. Please note that this approach may cause slight differences in $\mathrm{k}$-values compared to literature or theoretical values. For this proficiency test, we also accepted values for $\mathrm{Ca}$ and $\mathrm{Fe}$ obtained by summing the intensities of the $\mathrm{K} \alpha$ and $\mathrm{K} \beta$ peaks.

- Evaluation

Each of the $k$-values are worth one point.

\section{Part 4. Interpretation of an "abnormal" spectrum}

For this section of the proficiency test, laboratories were asked to respond to questions concerning an "abnormal" spectrum collected from SRM 2063. The spectrum was displayed with a linear and log scale (Figures 4a, b) and the peak counts were given in Table 5 of the proficiency-test instructions. The laboratories were asked to compare the spectrum to the "normal" spectrum of SRM 2063 given in Figure 3 of the proficiency-test instructions. 
This section was put into this proficiency test for educational purposes. It has been noted that some analysts have difficulty recognizing or interpreting "abnormal" $\mathrm{x}$-ray spectra. Problems were also noted in some of the laboratory count sheets from the first proficiency test that could have resulted from misinterpretation of $\mathrm{x}$-ray spectra. This section was not graded and therefore was not used to evaluate the laboratories' proficiency. The laboratories should, however, compare their answers to those given below.

1. What features are abnormal about this spectrum?

Acceptable answers are as follows:

1) The $\mathrm{Mg}$ and Si peaks are essentially absent.

2) The $\mathrm{Ca}$ peak is significantly reduced relative to the $\mathrm{Fe}$ and $\mathrm{Cu}$ peaks.

3) The continuum radiation does not have the characteristic shape usually present in energy dispersive spectra. The $\mathrm{x}$-ray background decreases noticeably from about 5.5 $\mathrm{keV}$ to below $1 \mathrm{keV}$.

2. How would one know that the spectrum was abnormal if the chemistry of the material was not known?

The unusual shape of the $x$-ray background is an indication that the spectrum is abnormal.

3. What are possible explanations for the abnormal spectrum if it is collected from all areas observed on an SRM 2063 sample?

The most general response to this question is that something is present between the sample and the detector that is causing abnormal absorption of $\mathrm{x}$-rays. Possible answers include:

1) There is an absorbing material on the detector window. The window may be coated with oil or ice.

2) There is a problem with the detector-sample geometry. For example, the detector may not be fully inserted or the sample holder could be at an improper tilt angle.

3) There is an absorbing material on the sample itself.

The most likely cause of the spectrum is the presence of oil or ice on the detector window. The detector window can accumulate oil or ice over time because its cool temperature provides a site for condensation of contaminants. For this case, the $x$-ray spectra collected from different areas of the grid would show the same degree of absorption at the lower energies. For the case of a problem with the sample-holder tilt angle, however, the $x$-ray spectra collected from different areas of the sample would likely differ slightly. This is because in different areas of the grid, different thicknesses of the sample holder would be between the sample and the detector. The presence of an absorbing material on the sample itself is a less likely cause. A layer thick enough to cause such absorption of $\mathbf{x}$ rays would cause problems with imaging of the sample.

Many incorrect responses were given by the laboratories. Some laboratories stated that the SRM was manufactured incorrectly. However, the presence of an "abnormal" background would indicate a different problem. In addition, Standard Reference Materials are tested extensively prior to and after production and though there is a possibility of a problem, other options should be checked first. Some laboratories postulated that the detector window is 
too thick Although this could create such a spectrum, the problem should have been noted upon receipt of the detector. Other laboratories stated that air or water vapor may be present in the microscope column thereby causing absorption of $\mathrm{x}$ rays. However, the loss of vacuum would affect the operation of the TEM. Finally, several laboratories postulated problems with the electronics of the detector-mca system (preamplifier, pulse processor, presence of ground loops, software problems, etc.). No such problem has been identified that would result in the spectrum of Figures $4 a, b$.

4. What are possible explanations for the abnormal spectrum if it is collected from one area of an SRM 2063 sample if other areas observed before and after the abnormal spectrum give the "normal" spectrum?

As for the previous case, it is likely that something is present between the sample and the detector that is absorbing the low-energy $x$ rays. However, as this was only a localized situation, contamination of the detector window is not the cause. Possible causes are:

1) There is a problem with the specimen-detector geometry. Examples include:

a) The sample holder is not at a correct angle to the detector and the sample holder is in the line of sight of the detector. $X$ rays are absorbed by the sample holder.

b) The sample is at a correct angle to the detector. However, $x$-ray spectra obtained from some portions of a grid (near the edges) can still be partially blocked by the sample holder.

c) The sample is too close to a grid bar. $\mathrm{X}$ rays are absorbed because the grid bar is between the sample and detector. This is usually a problem only if the grid is oriented above the sample.

2) There are large topographic changes in the sample. A portion of the sample is absorbing $x$ rays.

3) There is localized contamination of the sample.

The last two explanations are less likely as the TEM operator would probably notice an unusual image obtained under such conditions.

An incorrect explanation given by the laboratories is that the specimen is inhomogeneous. The presence of the abnormal background in the spectrum is an indication that absorption. not chemical inhomogeneities, is the problem. Another incorrect explanation is that there are problems with the electronics. As stated above, no such problem has been identified that would generate the spectrum of Figures $4 a, b$.

\section{Part 5. Magnification calibration}

The laboratories were given a color copy of a TEM micrograph of a carbon replica made from an optical grating and were asked to determine the magnification of the micrograph. A histogram of the values reported by the laboratories was made and the obvious outliers discarded. The mean value for the magnification and its standard deviation $(s)$ are given in the following table: 


\begin{tabular}{|c|c|}
\hline Mean & $s$ \\
\hline $27,402 \mathrm{x}$ & 158 \\
\hline
\end{tabular}

The values obtained by NIST personnel fall within one standard deviation of the mean given above. The reported magnifications considered acceptable for this proficiency test ranged from $26,700 \mathrm{x}$ to $28,100 x$.

\section{- Discussion of results}

The majority of laboratories used the correct method for deriving the magnification. Problems in the magnification determination occurred when laboratories measured a small number of lines - some laboratories measured only one, two or three lines. When such a small number of lines are measured, errors are introduced due to variations in the optical grating, distortions in the replica and from the measuring process itself. As many lines as possible should be measured for each magnification determination.

The standard deviation of the measurements was determined incorrectly by some laboratories. The following formula should be applied:

$$
s=\sqrt{\frac{\sum(X-M e a n)^{2}}{N-1}}
$$

where $X=$ a measurement value, Mean $=$ the mean of the measurement values and $N=$ the number of measurements.

- Evaluation

The magnification determination is worth one point.

Discussion of overall results of the laboratories

The results of the laboratory receiving this report are given in Appendix B. A laboratory passed this proficiency test if it accumulated less than two errors. Thirty-two laboratories did not pass this proficiency test.

\section{$\underline{\text { References }}$}

E.B. Steel, S. Tumer, H.W. Berger, NVLAP Program Handbook for Airborne Asbestos Analysis, National Institute of Standards and Technology, NISTIR 89-4137, 1989. 
Appendix A Suggestions for further reading

\section{k-factors}

G. Cliff, G.W. Lorimer, The quantitative analysis of thin specimens, J. of Microscopy, vol. 103, pp 203-207.

see the NVLAP handbook p. F5, item $10 \mathrm{~h}$ for additional references on $\mathrm{k}$-factors.

\section{$\underline{\text { EDS artifacts }}$}

J.I. Goldstein, D. E Newbury, P. Echlin, D.C. Joy, C. Fiori, E Lifshin, Scanning Electron Microscopy and X-ray Microanalysis, Plenum Press, New York, NY, 1981, pp 226-264. 
Page 34 of 46 
III. Instructions for PT91-2 
The major purpose of this proficiency test is to evaluate each laboratory's abilities to do the following:

- Obtain and record selected area electron diffraction patterns.

- Determine d-spacings from the diffraction patterns.

- Obtain, record and interpret EDXA spectra.

- Report results correctly.

Please read the following directions and examine the forms carefully before beginning the test.

1. The grid box included with the test contains a grid which is located in the center slot. This location is circled on the grid box cover. Place the grid in the electron microscope in the same manner and under the same instrument conditions used for asbestos analysis.

2. The grid has several materials deposited on its surface. Obtain a diffraction pattern and an EDXA spectrum from 3 different grains on the grid which have the following characteristics:

- The composition of the grains consists of mainly aluminum and silicon, and no potassium or calcium. Minor iron is acceptable.

- The grains are single crystals; i.e. they are not part of an agglomerate of several crystallites.

- The grains are electron transparent; i.e. they produce clear diffraction patterns.

- The diffraction patterns are zone-axis patterns that do not require orientation of the sample grain at $0^{\circ}$ stage tilt.

- All patterns should be of the same zone.

3. Photograph the diffraction patterns, and obtain hard copies of the EDXA spectra.

4. Label the diffraction patterns and the EDXA spectra with the following designations: Particle \#1, Particle \#2, and Particle \#3. Diffraction patterns may be labelled by writing both the negative ID\# and the Particle \# (1-3) on the negative carrier. 
5. Determine the three largest unique d-spacings on each of the 3 diffraction patterns. Record these d-spacings (using $\AA$ units) in the appropriate spaces on Form \#3, and show the work done in calculating the spacings on Form \#1. The d-spacing should be reported to two decimal places (to $0.01 \AA$ ).

6. Circle the measured diffraction spots on the negative of the diffraction pattern.

7. Calculate the mean and standard deviation of the largest d-spacings determined on the three diffraction patterns obtained from the three particles: Similarly, determine the mean and standard deviation for the second and third largest d-spacings. Record these values in the appropriate spaces on Form \#3. Show the method used to calculate these values on Form \#2.

8. Submit negatives of the three diffraction patterns and hard copies of the three EDXA spectra along with your results. Save the grid for training purposes. The grid may be recalled by RTI or NIST if necessary.

Note: The laboratories should be able to distinguish between reflections on a diffraction pattern that have $d$-values that differ by $0.1 \AA$ or more. For example, if a material has $d$-spacings of $5.20 \AA$ and $5.32 \AA$, the laboratory should be able to determine that these two spacings are different. The accuracy of d-spacing determination must be within $\pm 5 \%$ relative of the true value. 


\section{$\underline{\text { Form \#1 }}$}

Show the work done to determine the three largest d-spacings on each of the three diffraction patterns. Include the camera constant used and any measurements made directly from the diffraction patterns. Use additional sheets if necessary. 


\section{Form \#2}

In the space below, show the method used to calculate the means and standard deviations of the d-spacings. 
$\underline{\text { Form \#3 }}$

\begin{tabular}{||l||c|c|c||}
\cline { 2 - 4 } \multicolumn{1}{c|}{} & $\begin{array}{c}\text { Largest } \\
\text { d-spacing }(\AA)\end{array}$ & $\begin{array}{c}\text { Second largest } \\
\text { d-spacing }(\AA)\end{array}$ & $\begin{array}{c}\text { Third largest } \\
\text { d-spacing }(\AA)\end{array}$ \\
\hline \hline Particle \#1 & & & \\
\hline Particle \#2 & & & \\
\hline Particle \#3 & & & \\
\hline Mean & & & \\
\hline Standard deviation & & & \\
\hline
\end{tabular}


IV. Summary Report for PT91-2 
The information presented in this report is a summary of the analysis of materials and the performance of laboratories on the proficiency test sent to laboratories in the airborne asbestos program in October of 1991 (designated as test 91-2). Discussion of results for both the diffraction pattern analysis and of the structure print submission is given in the main portion of the report. The results obtained by the laboratory receiving this report are given in Appendix $A$ of the report.

\section{PART 1 - DIFFRACTION PATTERN ANALYSIS}

\section{Material sent to laboratories}

Laboratories were sent a carbon film grid containing a slurry of silicate layer materials. The laboratories were asked to obtain diffraction patterns and EDXA spectra from three different grains on the grid. The grains analyzed were to have the following characteristics: 1) their composition is mainly $\mathrm{Al}, \mathrm{Si}, 2$ ) the grains are single crystals that give clear diffraction patterns, 3) no orientation is required at $0^{\circ}$ stage tilt, and 4) the patterns are of the same zone. The material fitting these criteria corresponds to kaolinite. The source material was obtained from Fisher Scientific.

\section{Analysis of material}

The laboratories were asked to report the three largest unique d-spacings from the three diffraction patterns. To determine those values, the material was analyzed by NIST and RTI by two methods: 1) $x$-ray diffraction using internal mica and silica standards and 2) by electron microscopy using an internal gold standard. As shown below, the results obtained from the two techniques are not in complete agreement.

\section{$X-r a y$ diffraction}

The material was analyzed on a Philips PW1800 automated diffractometer equipped with an automatic divergent slit, copper radiation, and a graphite monochromator. The receiving slit was set to $0.3 \mathrm{~mm}$. The power settings used were $40 \mathrm{kV}$ and $55 \mathrm{~mA}$. Initially, a qualitative analysis was made of the material by scanning three slurry mounts from $5-90^{\circ} 2 \theta$ with a count time of two seconds per $0.01^{\circ} 2 \theta$ step. The diffraction patterns consist primarily of kaolinite peaks with some additional minor peaks attributable to mica.

The d-spacings for kaolinite were determined by spiking a portion of the bulk sample with both SRM $640 \mathrm{~b}$ (silicon) and SRM 675 (fluorophlogopite) as internal standards. Twelve backloaded powder mounts of the spiked material were prepared and scanned at six seconds per $0.01^{\circ} 2 \theta$ step over a range of at least $10-40^{\circ} 20$. A calibration curve was prepared from the internal standards and applied to the data to correct for any sample displacement. Profile fitting was used to determine peak locations.

A summary of the average d-spacings obtained for those reflections in the [001] zone of kaolinite and a comparison to those values found on JCPDS card 14-164 are given in Table 1: 
Table 1. Comparison of d-spacings obtained from $x$-ray diffraction (this work) to those given on JCPDS card 14-164 for reflections in the [001] orientation of kaolinite.

$\begin{array}{lll}\text { hikd } & \text { d-spacing } & \text { standard } \\ (14-164) & \text { (this work) } & \text { deviation }\end{array}$

(220)
$4.478 \AA$

4.366

2553

2.495

2237

2173
$4.46 \AA$

4.36

*

2.496

*

$\cdot$
$0.0036 \AA$

0.0018

0.0003

- were not determined due to peak overlaps

\section{Electron microscopy}

Two grid preparations from the same lot prepared for the proficiency test were covered with a gold film by sputtering. Diffraction patterns were obtained by two analysts on two instruments - a Hitachi H7000 and a JEOL 200CX.

A total of 21 diffraction patterns were obtained. The d-spacings for the six diffracted spots closest to the central spot in the pseudohexagonal diffraction pattern were determined by measuring the distance covered by two to ten of the diffracted spots in the appropriate row. The spacing of the fourth gold ring (corresponding to $1.23 \AA$ ) was measured in the six directions corresponding to the diffracted spots and used to derive camera constants for the diffraction patterns.

The average d-spacings and the range of d-spacings determined for the six diffracted spots in 21 [001] diffraction patterns are shown in Table 2:

Table 2 Average and range of d-spacings obtained by SAED analysis of 21 gold-coated specimens.

\begin{tabular}{llll}
$\begin{array}{l}\text { spot } \\
\text { number }\end{array}$ & d-spacing & $\begin{array}{l}\text { standard } \\
\text { deviation }\end{array}$ & range \\
\hline & & & \\
1 & $4.48 \AA$ & $0.02 \AA$ & $4.45-4.50 \AA$ \\
2 & 4.46 & 0.01 & $4.44-4.50$ \\
3 & 4.45 & 0.02 & $4.43-4.49$ \\
4 & 259 & 0.01 & $257-261$ \\
5 & 258 & 0.01 & $256-259$ \\
6 & 257 & 0.01 & $255-259$
\end{tabular}

The difference between spots $1-3$ ranged from 0.01 to $0.05 \AA$ and averaged $0.02 \AA$ The difference between spots $4-6$ ranged from 0.01 to $0.04 \AA$ and averaged $0.02 \AA$ 
Surprisingly, the results from $x$-ray diffraction and electron diffraction differ. The results of $x$-ray analysis correspond to those given by JCPDS card 14-164. The two largest distinguishable d-spacings are given by 4.46 and $4.36 \AA$ The results of electron microscopy analysis, however, do not show a spacing that corresponds to $4.36 \AA$ We at present do not know why there is a discrepancy between the two techniques. One speculation is that a slight change in the structure occurs in the vacuum of the electron microscope or by heating in the electron beam. If this is true, it is possible that different microscopes or different beam doses would affect the structure slightly differently.

\section{$\underline{\text { Results submitted by laboratories }}$}

One-hundred and thirty labs (main and subfacilities) submitted results for this proficiency test. The laboratories were asked to report the three largest unique d-spacings for the diffraction patterns. A variety of $d$-spacings were reported by the laboratories as the three largest.

The laboratories were graded on the value submitted for the largest d-spacing. The average value obtained by the laboratories is $4.47 \AA$ with a standard deviation of $0.12 \AA$ (obvious outliers were discarded in derivation of this value). This value compares well with the average value of $4.46 \AA$ obtained at NIST and RTI by both XRD and TEM analysis. As stated in the instructions for the proficiency test, the laboratories were expected to obtain a value within $5 \%$ of the true value (SAED is capable of $1 \%$ or better accuracy, but for most cases $5 \%$ accuracy is sufficient to distinguish asbestos minerals from nonasbestos minerals). Thus the laboratories should have obtained a value in the range of $4.46 \AA \pm 0.22 \AA$ Since this was the first time measurement of patterns obtained by the laboratory was tested, however, we accepted values in the range of 3.96 to $4.96 \AA$ Those laboratories that obtained values outside the range of 4.24 to $4.68 \AA$ should review and improve their procedure for analyzing diffraction patterns. Future tests of diffraction will require $5 \%$ accuracy.

Errors made by the laboratories include: 1) choosing an incorrect diffracted spot as having the largest d-spacing, 2) using a "radius" measurement for the camera constant and a "diameter" measurement for the d-spacing measurement (or the reverse) resulting in a halving or doubling of the derived $d$ spacing and 3) reporting the inverse of the d-spacing.

The values submitted for the second and third-largest d-spacings were not graded. There were two reasons for not evaluating these results. Firstly, laboratories interpreted the phrase "three largest unique d-spacings" in a variety of ways. Secondly, as discussed in the previous section, it is possible that different microscope conditions could affect the structure slightly differently leading to a variety of d-spacings.

The EDXA spectra submitted by the laboratories were reviewed. If any features of concern were observed on the EDXA spectra or SAED patterns, they are described in a note given in the Appendix to the cover letter.

\section{PART II - STRUCTURE PRINTS}

For the second part of this proficiency test, laboratories were asked to provide at least ten prints or negatives of air-collected samples that had been analyzed in their laboratory using the AHERA protocol. The laboratories were asked to identify the type of asbestos, the number of structures present and the loading of the filters from which the images were obtained. Although not required, the laboratories were additionally asked to provide an image of their calibration grating. 
One-hundred and twenty-one laboratories submitted either prints or negatives of asbestos analyzed in their laboratories. One of the laboratories submitted images of bulk asbestos samples. A total of 1292 prints or negatives were submitted that contained airborne asbestos. The types of asbestos reported by the laboratories (on a print or negative basis) are summarized in Table 3:

Table 3. Types of asbestos found on structure prints submitted by laboratories.

$\begin{array}{ll}\text { Chrysotile } & 94 \% \\ \text { Amosite } & 5 \% \\ \text { Tremolite } & 0.2 \% \\ \text { Anthophyllite } & 0.01 \% \\ \text { "amphibole" } & 1 \%\end{array}$

We were interested in determining the types of structures present on the prints and negatives. The asbestos structures were examined to determine if they were contained within the border of the negative or print. Ninety-eight of the laboratories had at least one negative or print with a fiber that was only partially in the field of view. The images from these laboratories were not used for further study, because the determination of the structure type from these labs could be either incomplete or biased.

The images from 22 laboratories were examined to determine the types of structures present. The 223 images were examined independently by two analysts and discrepancies were resolved in many cases. The total number of structures determined by the two analysts were 265 and 273, respectively. The structures were categorized using the counting rules given by EPA as modified by NIST. Five categories were used - single fiber, double fiber, bundle, matrix and cluster (a double fiber consists of two parallel, touching fibers). The distribution of structures is given in Table 4:

Table 4. Summary of types of structures on structure prints submitted by laboratories.

\begin{tabular}{lccc} 
& Analyst 1 & Analyst 2 \\
\cline { 2 - 2 } Single fiber & & \\
Double fiber & $45 \%$ & & $41 \%$ \\
Bundle & $9 \%$ & & $8 \%$ \\
Matrix & $18 \%$ & & $18 \%$ \\
Cluster & $21 \%$ & & $24 \%$ \\
& $7 \%$ & & $9 \%$
\end{tabular}

\section{$\underline{\text { Discussion }}$}

The submitted images are of use in several areas. Firstly, they provide a database of actual aircollected structures for future round robins that test the precision of counting rules. Secondly, they provide a database of structures for future proficiency tests of the laboratories' ability to apply counting rules. Thirdly, they provide a database from which the types of samples analyzed by the laboratories can be characterized. As shown in Tables 3 and 4, the relative distribution of asbestos types (chrysotile vs. amosite, etc.) and the distribution of structure types (single fibers vs. clusters, etc.) can be determined. We plan also to determine dimensional information from the prints. This information is useful background information for the production of testing materials used in the NVLAP proficiency testing program. It is also useful background information for the derivation of 
counting rules. Finally, the images provide evidence that the laboratories are capable of satisfying item $29 \mathrm{~g}$ in the checklist in the Handbook for Airborne Asbestos Analysis (Steel et al., 1989). This item requires that the laboratories are capable of recording bright field images on electron micrographs or other suitable media.

Tentative conclusions can be derived from the data. The conclusions are based on the assumptions that: 1) the data submitted by the laboratories are representative of those analyzed by all laboratories (it is a random sampling) and 2) the laboratories correctly analyze asbestos samples, i.e. amphiboles are identified if present. The images submitted show that chrysotile is by far the most predominant asbestos type analyzed by the laboratories. Amosite is the most predominant amphibole. Single fibers represent at least $40 \%$ of the structures analyzed and clusters and matrices represent over $25 \%$ of the structures analyzed.

\section{PART III - GRADING OF THE PROFICIENCY TEST}

The laboratories were graded on the determination of the largest d-spacing on the kaolinite diffraction pattern and on the submission of ten structure prints. The subfacilities were evaluated solely on their determination of the largest d-spacing. Their evaluation is for informational purposes only. Seven main laboratories did not pass this proficiency test.

\section{References}

E.B. Steel, S. Turner, H.W. Berger, NVLAP Program Handbook for Airborne Asbestos Analysis, National Institute of Standards and Technology, NISTIR 89-4137, 1989. 

